\title{
DEVELOPMENT OF AN ACTIVE FILM WITH NATURAL ZEOLITE AS ETHYLENE SCAVENGER
}

\author{
A. COLOMA' , F. J. RODRÍGUEZ ${ }^{2,3}$, J. E. BRUNA ${ }^{2,3}$, A. GUARDA ${ }^{2,3}$, M. J. GALOTTO ${ }^{2 *}$ \\ 1. Department of Agro-industries. Faculty of Agricultural Science. National University of the Altiplano, Puno, Perú \\ 2. Center for the Development of Nanoscience and Nanotechnology (CEDENNA), Food Packaging Laboratory (LABEN-CHILE). \\ Edificio Alimentos. Calle Obispo Umaña 050.Santiago. Chile \\ 3. Food Science and Technology Department. Faculty of Technology. University of Santiago de Chile, Santiago, Chile. Avda Ecuador 3769. Santiago. Chile.
}

\begin{abstract}
Ethylene $\left(\mathrm{C}_{2} \mathrm{H}_{4}\right)$ acts as a plant hormone, growth regulator that has a number of effects on the growth. Ethylene accelerates respiration, leading to maturity and also softening and ripening of many kinds of fruits. Although ethylene has some positive effects, it is often hazardous to the quality and shelf-life of fruits and vegetables. The removal of ethylene and/or inhibition of the effect of ethylene in stored environments is fundamental to maintaining postharvest quality of climacteric produce. In this study, the efficiency of a Chilean natural zeolite (NZ-Ch) against a commercial $\mathrm{Na}^{+}$montmorillonite $\left(\mathrm{Cloisite} \mathrm{Na}^{+}\right)$was studied. The aluminosilicate characterization (XDR, FTIR, EGME, CEC, chemical composition) indicates that natural Chilean zeolite belongs to mordenite group. Elemental chemical analysis indicated that compensating ions, were sodium for $\mathrm{MTNa}^{+}$and calcium, sodium and potassium for NZ-Ch, and in both aluminosilicates copper was present in their composition. Ethylene adsorption kinetics were fitted to a pseudo-second order model. The rate constant of the ethylene adsorption was nearly double for NZ-Ch compared with $\mathrm{MtNa}^{+}$. Langmuir-Freundlich isotherm allowed to determine maximum adsorption capacity that reached values of $5.4 \mu 1 \mathrm{~g}^{-1}$ for $\mathrm{NZ}-\mathrm{Ch}$ and $1.28 \mu \mathrm{g} \mathrm{g}^{-1}$ for $\mathrm{MtNa}^{+}$. Films of low density polyethylene (LDPE) were obtained with different NZ-Ch concentrations. After 50 hours, a removal of $37 \%$ of ethylene present on headspace was achieves with $10 \%$ of ZN-Ch in LDPE active films.
\end{abstract}

Keywords: Ethylene adsorption, $\mathrm{Na}^{+}$Montmorillonite, Natural Zeolite

\section{INTRODUCTION}

Ethylene $\left(\mathrm{C}_{2} \mathrm{H}_{4}\right)$ is a naturally occurred, simple two carbon gaseous component that acts as a plant hormone, growth regulator that has a number of effects on the growth, development and storage periods of many kinds of fruits, vegetables and ornamental crops. Ethylene accelerates respiration, leading to maturity and also softening and ripening of many kinds of fruits. Moreover, ethylene accumulation can result in yellowing of green vegetables and it is responsible for numerous types of specific postharvest defects in fresh fruits and vegetables. Although ethylene has some positive effects, it is often hazardous to the quality and shelf-life of fruits and vegetables ${ }^{1}$. Accumulation at trace levels of ethylene during the storage period may result in a number of specific defects and shorten the harvest shelf life $e^{2}$. The removal of ethylene and/or inhibition of the effect of ethylene in stored environments is fundamental to maintaining postharvest quality of climacteric produce ${ }^{3}$. In recent years, there has been a paucity of research on developing new and more efficacious ethylene scavenger materials. In contrast, there has been an exponential increase in research using the ethylene binding inhibitor 1-methylcyclopropene (1-MCP). Thus research activity has drifted away from ethylene removal to preventing the actions of ethylene through using 1-MCP.

Despite various ethylene scavenger technologies are available (e.g. high temperature catalytic degradation, activated carbon, etc.) most of the commercial ethylene control systems rely on both: adequate ventilation and oxidation of ethylene using potassium permanganate $\left(\mathrm{KMnO}_{4}\right)$-based mechanisms. Ventilation, however, is not appropriate in sealed environments (controlled atmosphere) or where precise ethylene control is required ${ }^{3}$.

In the last decades, materials such as zeolites and clays (crystalline aluminosilicates) that possesses ethylene adsorption capacity, have received much attention ${ }^{4,5}$.

Clays and zeolites are aluminosilicates, which differ, in their crystalline structure. Clays have a layered crystalline structure and the zeolites have a rigid, 3-dimensional crystalline structure consisting of a network of interconnected tunnel and cage ${ }^{6}$. Among clays, the montmorillonite is a natural layered clay, member of the smectite family. It is a 2:1 clay, meaning that it has two $\mathrm{SiO}_{4}$ tetrahedral sheets sandwiching a $\mathrm{AlO}_{6}$ central octahedral sheet. The presence of $\mathrm{Al}$ in the framework introduces negative charges that require the presence of charge balancing cations occupying interlaminar spaces ${ }^{7}$.

Zeolites are hydrated aluminosilicates of alkali and alkaline earth elements with unique crystal structures consisting of a three-dimensional framework of tetrahedral $\mathrm{SiO}_{4}$ and $\mathrm{AlO}_{4}$ in its framework structure ${ }^{4}$. The isomorphic substitution of $\mathrm{Si}$ by $\mathrm{Al}$, leads to a negative charge density in the zeolite lattice.
This charge is neutralized by introducing monovalent, divalent or trivalent cations in the structural sites of the zeolite ${ }^{8}$. Ion exchange of the balanced cations can result in clay and zeolites with specific properties such as selective adsorption. Erdogan et al. reported that natural zeolite (clinoptilolites) had considerable good ethylene removal properties ${ }^{9}$. They found that zeolites containing $\mathrm{K}^{+}$ions showed greater capacity for ethylene adsorption than zeolite exchanged with $\mathrm{Na}^{+}$and $\mathrm{Ca}^{2+}$. Sue-aok et al. reported the enhancement of ethylene adsorptivity upon modification of $\mathrm{NaY}$ zeolite by group I metal cations $^{8}$. Patdhanagul et al. demonstrated that zeolite NaY modified with phenyl trimethyl ammonium bromide (PTAB) as a cationic surfactant, is capable to modified only the external part of zeolite and not capable to enter the micropores of zeolite due to its large long chain, showing an appreciable increase in ethylene adsorption ${ }^{2,4)}$.

On the other hand zeolite modified with palladium presented a significant ethylene adsorption capacity $\left(4162 \mu \mathrm{Lg}^{-1}\right.$ material), far superior to $\mathrm{KMnO}_{4}$ based scavengers when used in low amounts $(10 \mathrm{mg}$ modified zeolite/L) and in conditions of high relative humidity ${ }^{3}$. Modified zeolite was capable to increase kiwi and banana shelf-life although no effect was observed for strawberry.

The purpose of the current study is to compare the efficiency of a Chilean natural zeolite against $\mathrm{Na}^{+}$montmorillonite as ethylene scavenger, in order to select the best aluminosilicate to be modified to improve ethylene adsorption capacity, for the development of a new active packaging system.

\section{EXPERIMENTAL PROCEDURE}

\section{Materials}

Montmorillonite, Cloisite ${ }^{\circledR} \mathrm{Na}^{+}\left(\mathrm{MtNa}^{+}\right)$, with a cationic exchange capacity (CEC) of $92.7 \mathrm{meq} / 100 \mathrm{~g}$ was obtained from Southern Clay Products Inc. (Texas, USA). A Chilean natural zeolite (NZ-Ch) was supplied by Maderas Bravo S.A. (Talca, Chile). Lineal low-density polyethylene (LLDPE) and low density polyethylene (LDPE), were supplied by Dow Petroquímica S.A. (Chile).

\section{Aluminosilicate characterization}

\section{Mineral moisture characterization}

Moisture of the zeolite mineral was evaluated by gravimetric means. $1 \mathrm{~g}$ of each one of the aluminosilicates were dried at $100^{\circ} \mathrm{C}$ for $24 \mathrm{~h}$ in an oven (Binder, FD115, Tuttlingen, Germany), cooled in a desiccator and its mass was monitored in a precision balance (MS204, Mettler Toledo Greifensee, 
Switzerland) until constant weight $( \pm 0.1 \mathrm{mg})$. The difference between the dried mass value and the equilibrium mass value was used to evaluate the moisture content ${ }^{10)}$.

Cation exchange capacity

Cation exchange capacity of the aluminosilicate was determined by chemical modification with $\mathrm{NH}_{4}^{+10}$. Aproximately $1 \mathrm{~g}$ of the aluminosilicate powder was mixed with $50 \mathrm{~mL}$ of $\left(\mathrm{NH}_{4}\right)_{2} \mathrm{SO}_{4}$ of a $0.25 \mathrm{~mol} \mathrm{~L}^{-1}$ and stirred for $16 \mathrm{~h}$ at room temperature. The final exchanged sample was centrifuged at 4000 $\mathrm{rpm}$ for $10 \mathrm{~min}$, and washed with deionized water and dried overnight at $80^{\circ} \mathrm{C}$. Sample was then titrated with $0.1 \mathrm{~mol} \mathrm{~L}^{-1} \mathrm{NaOH}$ standard solution. The cation exchange capacity was calculated from Equation 1.

$$
\operatorname{CEC}\left(\text { meq }^{-1}\right)=\frac{(B-A) \times C}{m}
$$

where: $\mathrm{CEC}$ is meq $\mathrm{g}^{-1} ; B$ : volume of $\mathrm{NaOH}$ used in the titration of blank $(\mathrm{mL})$; A: volume of $\mathrm{NaOH}$ used in the titration of the sample $(\mathrm{mL}) ; \mathrm{C}$ : concentration of $\mathrm{NaOH}(\mathrm{M})$; and $m$ : weight sample (g).

\section{Specific mass and specific surface area}

The specific mass of the mineral was determined by pycnometry ${ }^{11)}$. An amount of $10 \mathrm{~g}$ of aluminosilicate was inserted in a pycnometer with water at $25^{\circ} \mathrm{C}$ until fulfillment of the volume of the recipient and measured the different masses. Thus, using the known masses of water, sample and recipient, results obtained allowed to determine the specific mass of the mineral expressed in terms of $\mathrm{gcm}^{-3}$. The specific gravity was calculated from equation 2 .

$$
S g=\frac{W_{2}-W_{1}}{\left(W_{4}-W_{1}\right)-\left(W_{3}-W_{2}\right)}
$$

The specific surface area (SSA) of the aluminosilicate was evaluated by ethylene glycol monometil ether (EGME) adsorption method. A sample of 0.5 g of aluminosilicate was dried at $110^{\circ} \mathrm{C}$ for $24 \mathrm{~h}$. Approximately $3 \mathrm{~mL}$ of EGME was added to the material with a pipette and mixed together with a hand swirling motion to create uniform slurry. Afterward, samples were placed into a glass-sealed vacuum desiccator and allowed to equilibrate for $20 \mathrm{~min}$. As a drying agent, a mix of $100 \mathrm{~g} 40$-mesh anhydrous calcium chloride and $20 \mathrm{~mL}$ EGME desiccant was placed in a glass dish at the bottom of the desiccator. The desiccator was evacuated using a vacuum of $640 \mathrm{~mm} \mathrm{Hg}$. After the evacuation process, the samples were weighed every $10-12 \mathrm{~h}$ using an analytical balance (MS 204 Mettler Toledo, Greifensee, Switzerland). If the mass difference between the two measurements was more than $0.001 \mathrm{~g}$, then the samples were placed into the desiccator again for additional vacuum. This process was continued until the sample weight did not change more than $0.001 \mathrm{~g}^{12}$.

The quantity of EGME to cover $1 \mathrm{~m}^{2}$ of material surface with a monomolecular layer is $2.86 \times 10^{-4} \mathrm{~g}$. The specific surface can be then calculated from the equation 3 .

$$
S S A_{E G M E}=\frac{w_{a}}{0.000286 w_{S}}
$$

where the SSA is in $\mathrm{m}^{2} \mathrm{~g}^{-1} ; W a=$ weight of EGME retained by the sample in grams; $0.000286=$ weight of EGME required to form a monomolecular layer on a square meter of surface $\left(\mathrm{gm}^{-2}\right)^{12)}$; and $W s=$ weight of soil in grams.

\section{Particle size distribution}

For the particle size analyses distribution of the minerals, $10 \mathrm{~g}$ sample was dispersed overnight in a mixture of $10 \mathrm{ml}$ of sodium pyrophosphate solution at $5 \% \mathrm{w} / \mathrm{v}$ and $200 \mathrm{~mL}$ of double distilled water, keeping under stirring for $16 \mathrm{~h}$. Thereafter, the sand size particles were separated from the suspensions by wet sieving through a $53-\mu \mathrm{m}$ sieve. The fraction retained by the sieve was dried and then weighed. The clay fraction $(<2 \mu \mathrm{m})$ was determined using the pipette method. The silt fraction $(50 \mu \mathrm{m}-2 \mathrm{~mm})$ was determined by difference ${ }^{12)}$. Analyses were performed in triplicates.

\section{Chemical analysis}

Samples $(2 \mathrm{~g})$ were weighed and mixed with $20 \mathrm{~mL} \mathrm{HNO}_{3}$. After heating $\left(100{ }^{\circ} \mathrm{C}\right)$ for $16 \mathrm{~h}$, until complete evaporation of $\mathrm{HClO}_{4}$, samples were left to cool at room temperature; $100 \mathrm{~mL}$ were gauged, filtered and measured in an inductively coupled plasma optical emission spectrophotometer (VARIAN Liberty RL Sequential ICP-OES, Mulgrave, Australia) ${ }^{13)}$.

\section{X-ray diffraction (XRD)}

XRD analysis was carried out in a Siemens Diffractometer D5000 (30 mA and $40 \mathrm{kv})$ using $\mathrm{CuK} \alpha(\mathrm{l}=1.54 \AA)$ radiation at room temperature. All scans were performed in a $2 \mathrm{q}$ range $2-80^{\circ}$ at $0.02^{\circ} / \mathrm{seg}$.

\section{Fourier transform infrared (FTIR)}

This spectroscopic analysis was carried out in a Bruker IFS 66V spectrometer (Bruker Alpha, Ettlingen, Germany). The aluminosilicates were crushed and blended with $\mathrm{KBr}$. Spectra were taken with $4 \mathrm{~cm}^{-1}$ resolution in a wave-number range from $4000-400 \mathrm{~cm}^{-1}$ with an average of 32 scans.

Ethylene adsorption

All ethylene adsorption experiments were carried out a room temperature $\left(25^{\circ} \mathrm{C}\right)$ in unstirred cell adsorption (Figure 1). Approximately $0.5 \mathrm{~g}$ of the sample, previously dried at $250{ }^{\circ} \mathrm{C}$ for $24 \mathrm{~h}$, was placed in a cell adsorption and sealed. Nitrogen:ethylene gas mixture $(9.6 \mathrm{ppm} \mathrm{v} / \mathrm{v})$ were injected in the adsorption cell. Gas samples were extracted from the cell using a $5 \mathrm{~mL}$ syringe at 30 min intervals and analyzed in a gas chromatograph Perkin Elmer Clarus 500 (Shelton, USA) fitted with a flame ionization detector (FID) with a $0.53 \mathrm{~mm}$ I.D. and $50 \mathrm{~m}$ length capillary column $\mathrm{Rt}^{\mathrm{TM}}$-Alumina PLOT. Oven and detector temperature were $100{ }^{\circ} \mathrm{C}$ and $250{ }^{\circ} \mathrm{C}$ respectively. Ethylene was calibrated against $9.6 \mu \mathrm{L} \mathrm{L}^{-1}$ ethylene balanced in $\mathrm{N}_{2}$ (Linde Gas Chile S.A., Santiago, Chile). Helium gas was used as carrier at a flow of $10 \mathrm{~mL} / \mathrm{min}$.

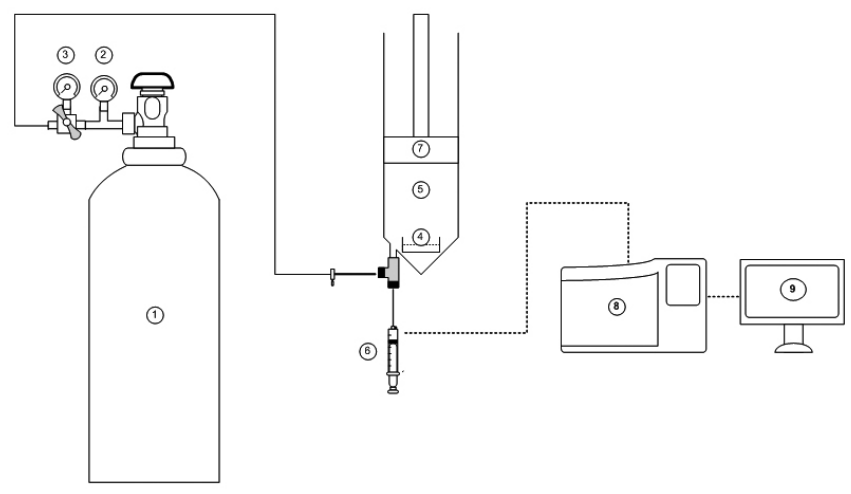

Figure 1: Schematic design of the volumetric adsorption system for aluminosilicates. (1) ethylene cylinder; (2) cylinder manometer; (3) mass flow meters; (4) sample; (5) adsorption cell; (6) sampling syringe; (7) Embolus; (8) gas chromatographic; (9) computer.

Adsorbed amount of ethylene $\left(q_{e}\right)$, was expressed as removed volume per mass unit of adsorbent material $\left(\mathrm{mL} \mathrm{g}^{-1}\right)$, and was calculated from the experimental data $\left[C_{i}, C_{f}, V_{L} \mathrm{y} m\right]$ in each sample according to the equation 4:

$$
q_{e}=\frac{\left\lfloor c_{i}-c_{f}\right\rfloor \times V}{m}
$$

where $V$ is the free volume of the cell adsorption $(\mathrm{L}), C_{i}$ is the initial concentration in the cell adsorption $\left(\mu 1 \mathrm{~L}^{-1}\right), C_{f}$ is the final concentration in the cell adsorption $\left(\mu 1 \mathrm{~L}^{-1}\right), \mathrm{m}$ is the mass of adsorbent material $(\mathrm{g})$.

\section{Adsorption Kinetics model}

Adsorption kinetics is one of the most important parameters for determining the adsorption mechanism and also to investigate the efficacy of adsorbent for removal of ethylene. In this study kinetic model pseudo-first order was used to predict the sorption behavior of the data ${ }^{14,15)}$.

$$
\ln \left(q_{e}-q_{t}\right)=\ln q_{\theta}-k_{1} t
$$

where $q_{e}\left(\mu \mathrm{L} \mathrm{g}^{-1}\right)$ and $q_{t}\left(\mu \mathrm{L} \mathrm{g}^{-1}\right)$ are the amount of ethylene adsorbed by aluminosilicate at equilibrium conditions, and at time $(t)$, respectively. $k_{l}\left(\mathrm{~h}^{-}\right.$ $\left.{ }^{1}\right)$ is the rate constant of pseudo-first-order kinetic model ${ }^{16)} . k_{1}$ and $q_{e}$ were determined from the slope and intercept of $\ln \left(q_{e}-q_{t}\right)$ versus $t$, respectively. The pseudo-second-order model was also fitted to the adsorption data using the following equation: 


$$
\frac{t}{q_{t}}=\frac{1}{k_{2} q_{e}^{2}}+\frac{t}{q_{e}}
$$

Where $k_{2}\left(\mathrm{~g} \mu \mathrm{l}^{-1} \mathrm{~h}^{-1}\right)$ is the constant of pseudo-second order.

\section{Adsorption Isotherms model}

The experimental adsorption isotherms of ethylene on material adsorbent were fitted to the Langmuir-Freundlich isotherm model, equation 7:

$$
q^{*}=\frac{q_{m} b c_{\theta}\left(\frac{1}{n}\right)}{1+b c_{\theta}^{\left(\frac{1}{n}\right)}}
$$

where $q^{*}$ is the adsorbed amount at equilibrium concentration $C_{e}, q_{m}$ the saturated adsorbed amount, $b$ and $n$ are the isotherm parameters. ' $b$ ' represents the strength of the interaction between the adsorbate and the adsorbent, and ' $n$ ' can be regarded as the parameter characterizing the system heterogeneity ${ }^{177}$.

Ethylene adsorption kinetic curves were fitted using the program OriginPro8.

\section{Preparation of active films}

In order to favor a good mixing between the LDPE and NZ, a 70:30\% $\mathrm{w} / \mathrm{w}$ mixture of LDPE/NZ-Ch masterbatch was previously prepared. The compounding processes of masterbatch production was performed using a co-rotating twin-screw extruder LabTech Scientific LTE20 (Bangkok, Thailand) having a screw diameter of $20 \mathrm{~mm}$ and a barrel length of $800 \mathrm{~mm}$ $(L / D=40)$. The LDPE/NZ-Ch powdery mixture was fed into the hopper by gravimetric dosing. The mixed compounds extruded through a round die was immediately passed through a LabTech Scientific LW-100 (Bangkok, Thailand) cold-water bath, and then the solidified long strands of composite were pelletized in a LabTech Scientific LZ-120 (Bangkok, Thailand) at 8 $\mathrm{rpm}$. The temperature profiles of extruder from Zone 1 to Zone 10 were kept between 115 and $130^{\circ} \mathrm{C}$. The twin-screw speed and single screw hopper feeder were fixed at $40 \mathrm{rpm}$.

Masterbatch was diluted with LDPE pellets to prepare LDPE/NZ-Ch films with different content of NZ-Ch: 2.5, 5.0, 7.5 and $10.0 \%$ w/w. Corresponding mixture of masterbatch and LDPE pellets was processed into a co-rotating twin-screw extruder LabTech Scientific LTE20 (Bangkok, Thailand) with a wide die $(200 \mathrm{~mm})$. The temperature profiles of extruder from Zone 1 to Zone 10 were kept between 170 and $185^{\circ} \mathrm{C}$. The twin-screw speed was fixed at 80 $\mathrm{rpm}$ and single screw hopper feeder was fixed at $50 \mathrm{rpm}$. Films extruded were collected in a chill roll attachment LabTech Scientific LBCR-150 (Bangkok, Thailand) at $5 \mathrm{~m} / \mathrm{s}$.

\section{Ethylene adsorption of active films}

The ethylene concentration was quantified using a GC-gas chromatograph as described above. Films of $10 \times 5 \mathrm{~cm}(10 \mathrm{~g})$ were placed in a $0.25 \mathrm{~L}$ flask and plugged with a rubber cap. The cap was equipped with two pipes, with one being the inlet and the other the outlet for the ethylene gas. The gas sample of $1 \mathrm{~mL}$ from the headspace of a 0.25 -L flask was injected into the gas chromatograph to determine the ethylene concentration for 10 days. The ethylene adsorption capacity was calculated by subtraction of the initial ethylene concentration from the measured ethylene concentration.

\section{RESULTS AND DISCUSSION}

\section{Physicohemical characteristics of the aluminosilicates}

The main physicochemical characteristics of the $\mathrm{MtNa}^{+}$and NZ-Ch are shown in Table 1. Moisture content of the aluminosilicates were $4.40 \%$ and $5.16 \%$ for $\mathrm{MtNa}^{+}$and $\mathrm{NZ}-\mathrm{Ch}$ respectively, values that are in accordance with those reported for commercial montmorillonite $(4-9 \%)^{18}$. Nevertheless, moisture of NZ-Ch are much higher than value reported for natural zeolite $(2.5 \%)^{11)}$. Specific mass ranged from $2.19 \mathrm{~g} \mathrm{~cm}^{-3}$ to $2.59 \mathrm{~g} \mathrm{~cm}^{-3}$ for $\mathrm{MtNa}^{+}$and NZ-Ch respectively. These values are also in accordance with those reported for montmorillonite $\left(2.50-2.76 \mathrm{~g} \mathrm{~cm}^{-3}\right)^{12,19)}$ and zeolites $\left(2.36-2.39 \mathrm{~g} \mathrm{~cm}^{-3}\right)^{11,12}$.

\section{Size distribution analyze}

The size distribution analyze showed that $100 \%$ of the particles have minor size of $45 \mu \mathrm{m}\left(\mathrm{MtNa}^{+}\right)$and a minor size of $75 \mu \mathrm{m}$ for NZ-Ch (Table 1).
Table 1: Main characteristics of the $\mathrm{MtNa}+\mathrm{y}$ NZ-Ch.

\begin{tabular}{|l|c|c|}
\hline Characteristics & $\mathbf{M t ~ N a}^{+}$ & NZ-Ch \\
\hline Moisture (\%) & $4.40 \pm 0.16$ & $5.16 \pm 0.09$ \\
\hline Specific gravity $\left(\mathrm{g} \mathrm{cm}^{-3}\right)$ & $2.59 \pm 0.23$ & $2.19 \pm 0.06$ \\
\hline Surface area EGME $\left(\mathrm{m}^{2} \mathrm{~g}^{-1}\right)$ & $606.7 \pm 14.4$ & $49.80 \pm 0.52$ \\
\hline Cation-exchange capacity $\left(\mathrm{meq} \mathrm{g}^{-1}\right)$ & $1.11 \pm 0.08$ & $1.94 \pm 0.05$ \\
\hline
\end{tabular}

The particle size distribution is related with the kinetics of the ionexchange ${ }^{10)}$. Particle size distribution of $\mathrm{MtNa}^{+}$and NZ-Ch obtained through the pipette method based on Stoke's law are shown in Table 2. It can be observed that $\mathrm{MtNa}^{+}$particle diameters are lower than those of the NZ-Ch. This is evidenced by observing that $99 \%$ of the particles of $\mathrm{MtNa}^{+}$have a diameter lower than $20 \mathrm{~mm}$, while in the case of zeolite only $75 \%$ of the particles have a diameter under this value. The particle size has an important role in processes of adsorption and desorption, since a smaller particle size means a greater contact surface for adsorbing determined substances. From these values it is expected that $\mathrm{MtNa}^{+}$present greater ethylene adsorption capacity than NZ-Ch.

Table 2: Particle size distribution.

\begin{tabular}{|c|c|c|}
\hline Particle size (mm) & $\mathbf{M t ~ N a}^{+} \mathbf{( \% )}$ & NZ-Ch $(\mathbf{\%})$ \\
\hline$f<2$ & $81.46 \pm 0.12$ & $20.2 \pm 0.05$ \\
\hline $2<f<20$ & $18.23 \pm 0.89$ & $54.4 \pm 1.40$ \\
\hline $20<f<50$ & $0.31 \pm 1.02$ & $21.9 \pm 1.10$ \\
\hline$f>50$ & $0.00 \pm 0.00$ & $3.5 \pm 0.30$ \\
\hline
\end{tabular}

\section{Specific surface area}

Polar liquid retention methods measure the total specific surface area (SSA) of the minerals, although the EGME method can partially measure internal surfaces of soils. In Table 1 it can be observed the differences in SSA values for both aluminosilicates, reaching values of $607 \mathrm{~m}^{2} \mathrm{~g}^{-1}$ for $\mathrm{MtNa}^{+}$and $49.8 \mathrm{~m}^{2} \mathrm{~g}^{-1}$ for NZ-Ch. Similar values, $615-815 \mathrm{~m}^{2} \mathrm{~g}^{-1}$ have been reported for natural montmorillonite from North Patagonia, Argentina ${ }^{20)}$ and $25.5-30.1 \mathrm{~m}^{2}$ $\mathrm{g}^{-1}$ for natural New Zealands zeolites (mordenite) ${ }^{21}$. The different structure of $\mathrm{MtNa}^{+}$(a laminar structure) compared with a porous structure of zeolites justify the differences on the SSA values observed for both minerals.

\section{Cation exchange capacity}

The cation exchange capacity (CEC) considers the capacity of the intrinsic ions of the minerals to be exchanged for other species with the same electrical charge. CEC for $\mathrm{MtNa}^{+}$was 1.11 (meq g ${ }^{-1}$ ) meanwhile for $\mathrm{NZ}-\mathrm{Ch} \mathrm{CEC}$ value reached $1.94\left(\mathrm{meq} \mathrm{g}^{-1}\right)$. These values are in accordance with those reported for montmorillonite $\left(1.10 \mathrm{meq} \mathrm{g}^{-1}\right)^{16,22}$. Higher CEC values for zeolites have also been reported, with values nearby $2.05 \mathrm{meq} \mathrm{g}^{-1}{ }^{10)}$. Studies indicate that the generation of negative charge of aluminosilicate minerals is due to the isomorphic substitution between silicon and aluminum atoms. The adsorption properties of gaseous substances depend largely on the exchangeable cations that are much more important for zeolites with a porous structure ${ }^{23,24)}$.

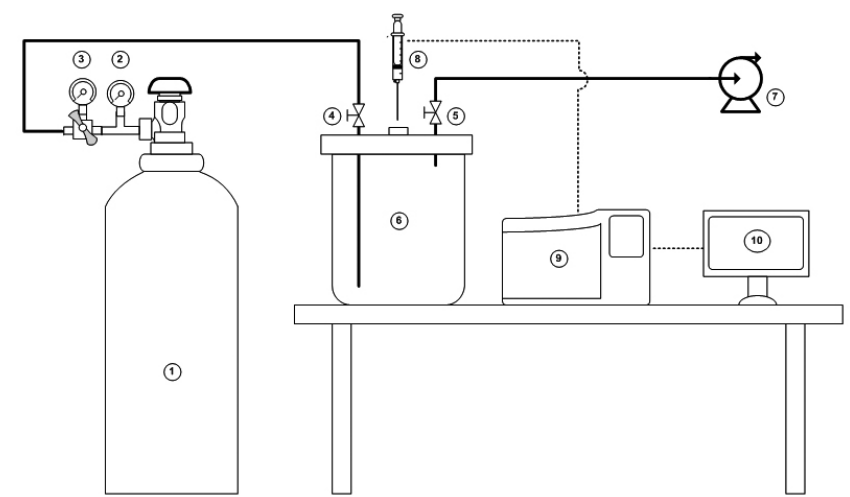

Figure 2: Schematic design of the volumetric adsorption system for films. (1) ethylene cylinder; (2) cylinder manometer; (3) mass flow meters; (4 and 5) valves; (6) adsorption cell; (7) vacuum pump; (8) sampling syringe; (9) gas chromatographic; (10) computer. 
Elemental chemical analysis

Chemical composition of $\mathrm{MtNa}^{+}$and NZ-Ch obtained by elemental chemical analysis are present in Table 3. The main chemical elements for both aluminosilicates, are silicon $\left(71.05 \% \mathrm{w} / \mathrm{w}\right.$ for $\mathrm{MtNa}^{+}$and $79.05 \% \mathrm{w} / \mathrm{w}$ for NZ-Ch) and aluminum $\left(6.60 \% \mathrm{w} / \mathrm{w}\right.$ for $\mathrm{MtNa}^{+}$and $4.05 \% \mathrm{w} / \mathrm{w}$ for $\left.\mathrm{NZ}-\mathrm{Ch}\right)$ Results of the chemical analysis showed that the natural zeolites contains a complement of exchangeable cations such as $\mathrm{Ca}^{2+}, \mathrm{K}^{+}, \mathrm{Mg}^{+}, \mathrm{Na}^{+}$and $\mathrm{Fe}^{3+}$. As expected, the main compensating cation present in montmorillonite was sodium ( $2 \mathrm{wt} \%$ ) because it is a commercial modified montmorillonite (Cloisite $\left.\mathrm{Na}^{+}\right)$. For NZ-Ch the main compensating cations were calcium, $(1.7 \mathrm{wt} \%)$, sodium (1.04 wt \%) and potassium ( $0.79 \mathrm{wt} \%)$. These cations have importance roles in ion-exchange with other cations in solution such as ammonium ${ }^{25}$. Interestingly, both aluminosilicate presented a low content of copper, however this content was double for NZ-Ch $\left(12.3 \mathrm{mg} \mathrm{kg}^{-1}\right)$ than for $\mathrm{MtNa}^{+}\left(5.5 \mathrm{mg} \mathrm{kg}^{-1}\right)$. The $\mathrm{Cu}^{2+}$ cations favors olefin adsorption, they act as active sites of adsorption gas on aluminosilicates ${ }^{26}$

Table 3: Chemical composition of the $\mathrm{MtNa}^{+}$y NZ-Ch.

\begin{tabular}{|c|c|c|}
\hline Element & Mt Na $^{+}$ & NZ-Ch \\
\hline Silicon, \% w/w & $71.05 \pm 3.40$ & $79.05 \pm 1.48$ \\
\hline Aluminum, \% w/w & $6.60 \pm 0.42$ & $4.05 \pm 0.49$ \\
\hline Magnesium, \% w/w & $0.30 \pm 0.03$ & $0.13 \pm 0.04$ \\
\hline Calcium, \% w/w & $0.39 \pm 0.02$ & $1.70 \pm 0.14$ \\
\hline Iron, \% w/w & $1.90 \pm 0.00$ & $1.15 \pm 0.07$ \\
\hline Sodium, \% w/w & $2.00 \pm 0.14$ & $1.04 \pm 0.08$ \\
\hline Potassium, \% w/w & $0.08 \pm 0.01$ & $0.79 \pm 0.01$ \\
\hline Copper, $\mathrm{mg} / \mathrm{Kg}$ & $4.60 \pm 1.27$ & $9.95 \pm 3.32$ \\
\hline
\end{tabular}

\section{$X$-ray difracetion analysis}

Figure 3 shows XRD diffraction patterns of $\mathrm{MtNa}^{+}$and $\mathrm{NZ}-\mathrm{Ch}$. $\mathrm{MtNa}^{+}$ shows the characteristic pattern for Cloisite $\mathrm{Na}^{+}$, with a basal spacing between the clay layers appeared at $2 \mathrm{q}=7.49^{\circ}$, corresponding to $1.18 \mathrm{~nm}^{27,28)}$. On the other hand, XRD diffraction analysis of natural zeolite showed that the positions and intensities of many of the reflections peaks at $2 \mathrm{q}=6.58^{\circ}, 9.84^{\circ}$, $13.54^{\circ}, 15.40^{\circ}, 19.74^{\circ}, 22.34^{\circ}, 25.78^{\circ}, 27.78^{\circ}, 32.04^{\circ}$ and $35.78^{\circ}$ correspond to the literature data of mordenite ${ }^{29,30,31)}$, as the predominant phase $^{32}$.

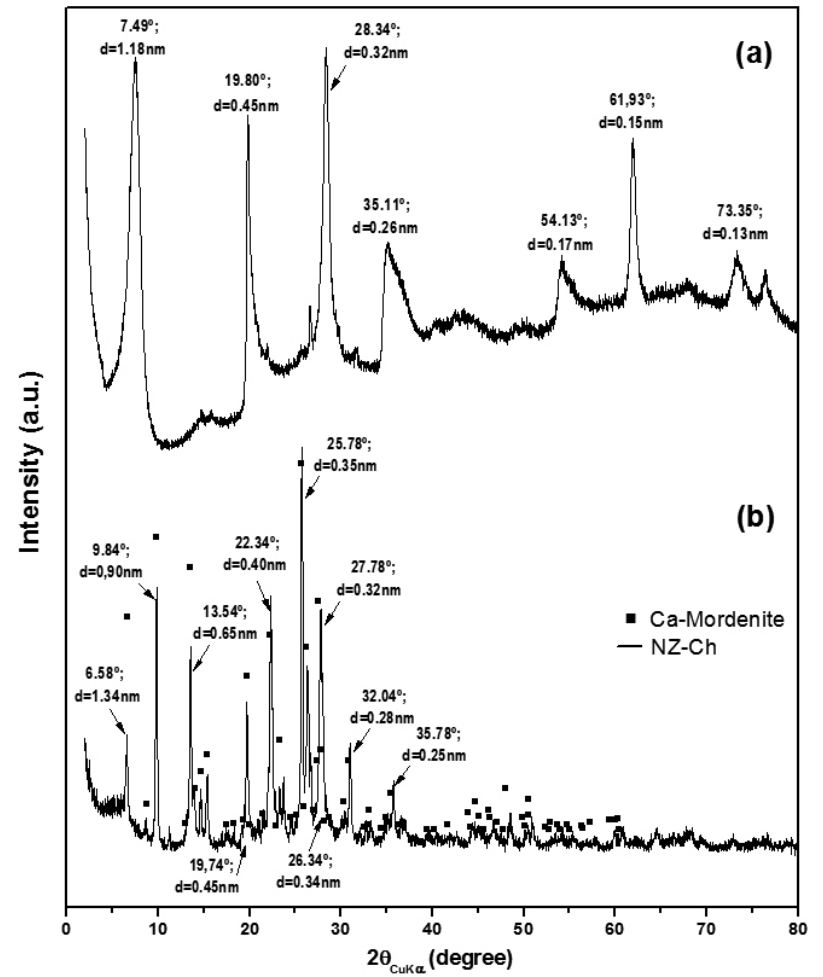

Figure 3: XRD patterns between $2 \theta=2.00^{\circ}-80.00^{\circ}$ of (a) $\mathrm{MtNa}^{+}$and (b)
Fourier Transform Infrared Analysis

Figure 4 presents FTIR spectra of $\mathrm{MtNa}^{+}$and NZ-Ch, that include bands at $\sim 3635 \mathrm{~cm}^{-1}$ and $\sim 3437 \mathrm{~cm}^{-1}$, associated with the stretching modes of Si-OH and $\mathrm{OH}$ groups of the interlayer water. A band at $\sim 1640 \mathrm{~cm}^{-1}$ attributed to the $-\mathrm{OH}$ bending of absorbed water, and $\sim 1045 \mathrm{~cm}^{-1}$ corresponding to Si-O stretching ${ }^{33}$, 34, 28). Other bands characteristic are $\sim 1067, \sim 796$ and $\sim 469$. The $\sim 1067 \mathrm{~cm}^{-1}$ band corresponds to asymmetric stretching vibration modes of internal $\mathrm{T}-\mathrm{O}$ bonds in $\mathrm{TO}_{4}$ tetrahedra ( $\mathrm{T}=\mathrm{Si}$ and $\mathrm{Al}$ ). The $\sim 796$ and $\sim 469 \mathrm{~cm}^{-1}$ bands are assigned to the stretching vibration modes of $\mathrm{O}-\mathrm{T}-\mathrm{O}$ groups and the bending vibrations of T-O bonds, respectively ${ }^{35}$.

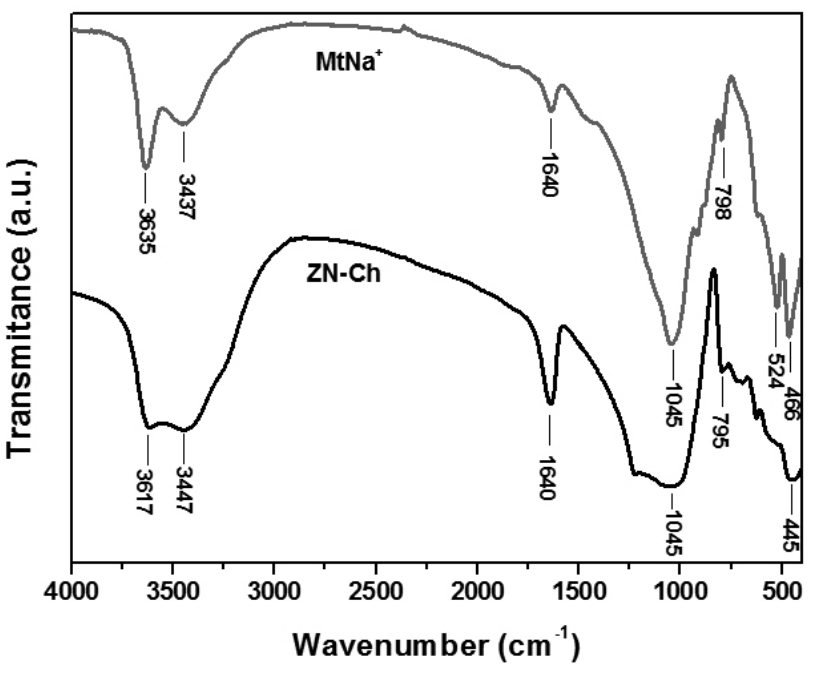

Figure 4: The FTIR spectra of $\mathrm{MtNa}^{+}$and NZ-Ch.

\section{Ethylene Adsorption}

The parameters for pseudo-first and pseudo-second-order kinetic models are listed in Table 4. As it can be seen, although both model well fitted experimental data, the pseudo-second-order model fitted the best with a correlation coefficient of 0.993 for $\mathrm{MtNa}^{+}$and 0.999 for NZ-Ch. Moreover, the $\mathrm{q}_{\mathrm{e}}$ calculated $\left(\mu \mathrm{L} \mathrm{g}^{-1}\right)$ achieved using the pseudo-second-model is much similar to the $\mathrm{q}_{\mathrm{e}}$ experimental $\left(\mu \mathrm{L} \mathrm{g}^{-1}\right)$, than the obtained with the pseudo-firstorder model. Figure 5 shows a plot of pseudo-second-order kinetic model for the ethylene adsorption for $\mathrm{MtNa}^{+}$and NZ-Ch. For $\mathrm{MtNa}^{+}$equilibrium is reached after $60 \mathrm{~min}$, meanwhile NZ-Ch reached equilibrium in $30 \mathrm{~min}$. When equilibrium is reached in short periods of time, indicates that the adsorption mechanism is governed by physical interactions, meanwhile long periods of time to reach equilibrium, indicates chemical adsorption or difficulty of accessing the active sites of the adsorbent surface ${ }^{36}$. On the other hand, the

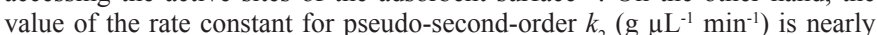
double for NZ-Ch compared with $\mathrm{MtNa}^{+}$. The pore size of zeolite plays an important role on adsorption properties. The larger pore diameter $(12 \AA)$ reported for a natural zeolite, favour that ethylene (kinetic diameter $3.9 \AA$ ) can pass through zeolite pore openings ${ }^{1}$, and can be absorbed within the zeolite framework. Two important interactions have been use to describe ethylene adsorption phenomena, first a cation-p interaction which occurs between $\mathrm{p}$-electrons of double bond of ethylene and metal cations, which involves $\mathrm{s}$-donation and $\mathrm{p}^{*}$ back donation between the metal cations and de $p$ orbital of ethylene, and also a CH-O interaction, a weak hydrogen bonding between hydrogen atoms of ethylene and oxygen atoms at the zeolite surface, which is weakly electropositive ${ }^{2,4)}$.

Table 4: Adsorption kinetics parameters on $\mathrm{MtNa}^{+} \mathrm{y}$ NZ-Ch.

\begin{tabular}{|c|c|c|c|c|c|c|c|}
\hline \multirow[b]{2}{*}{ Sample } & \multirow[b]{2}{*}{$\begin{array}{c}\mathrm{q}_{\mathrm{e}, \mathrm{exp} .} \\
(\mu \mathrm{L} \\
\left.\mathrm{g}^{-1}\right)\end{array}$} & \multicolumn{3}{|c|}{ Pseudo-first-order model } & \multicolumn{3}{|c|}{ Pseudo-second-order model } \\
\hline & & $\begin{array}{c}\mathrm{q}_{\mathrm{e}, \text { cal }} \\
\left(\mu \mathrm{L}^{-1}\right)\end{array}$ & $\begin{array}{c}K_{I} \\
\left(\mathrm{~min}^{-1}\right)\end{array}$ & $\mathrm{R}^{2}$ & $\begin{array}{c}\mathrm{q}_{\mathrm{e}, \text { cal. }} \\
\left(\mu \mathrm{L} \mathrm{g}^{-1}\right)\end{array}$ & $\begin{array}{c}\mathrm{K}_{2} \\
\left(\mathrm{~g} \mu \mathrm{L}^{-1}\right. \\
\left.\mathrm{min}^{-1}\right)\end{array}$ & $\mathrm{R}^{2}$ \\
\hline $\mathrm{MtNa}^{+}$ & 0.155 & 0.1472 & 0.0453 & 0.988 & 0.1575 & 0.7084 & 0.993 \\
\hline NZ-Ch & 0.885 & 0.8698 & 0.2015 & 0.987 & 0.8868 & 1.3375 & 0.999 \\
\hline
\end{tabular}




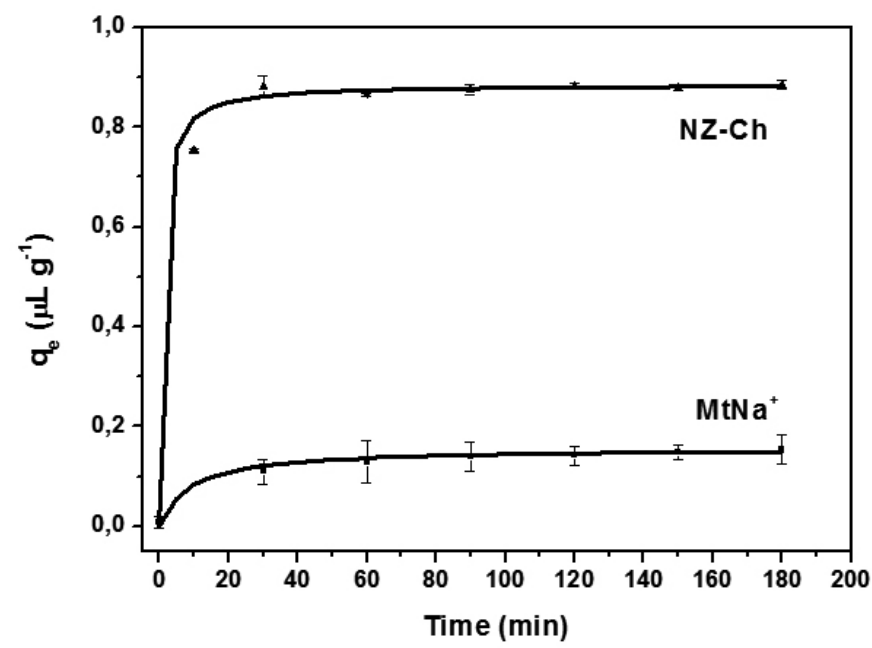

Figure 5: Ethylene adsorption kinetics on $\mathrm{MtNa}^{+}$y NZ-Ch. $\mathrm{Co}=9.6 \mathrm{ppm}$ ; $\mathrm{T}=25^{\circ} \mathrm{C} ; \mathrm{P}=1 \mathrm{~atm}$

\section{Adsorption isotherms}

Adsorption isotherm is one of the most important parameters to find the adsorption mechanism. Langmuir isotherm model can be applied for the determination of the maximum monolayer adsorption capacity of the adsorbent. The ethylene gas adsorption isotherms, expressed as absolute amount of ethylene adsorbed per gram of adsorbent are shown in Figure 6. The curves are similar in shape, and have classic isotherm type I form ${ }^{1)}$. The values of the constants in the models and the correlation coefficients obtained are summarized in Table 5. The applicability of Langmuir-Freundlich isotherm suggests a monolayer coating of ethylene molecules onto aluminosilicates surface. From the Langmuir-Freundlich parameters the maximum adsorption of ethylene capacity $\left(\mathrm{q}_{\mathrm{m}}\right)$ were calculated, being $1.28 \mu \mathrm{g}^{-1}$ for $\mathrm{MtNa}^{+}$y $5.42 \mu 1$ $\mathrm{g}^{-1}$ for NZ-Ch, which shows clearly that the NZ-Ch presents higher adsorption capacity compared with $\mathrm{MtNa}^{+}$, indicating a high affinity between the adsorbent and the adsorbate. This result was not expected due to the physicochemical properties initially reported, where $\mathrm{MtNa}^{+}$presented a smaller particle size and higher specific surface area. Nevertheless, the porous structure of zeolites favours the adsorption mechanism, and on the other hand zeolite presented higher amount of copper and calcium, and divalent cations in zeolites are known to be strong adsorptive center ${ }^{1)}$. It has been reported chabazite-type zeolite to remove $94 \%$ of ethylene incorporated in a jar with $48 \%$ relative humidity ${ }^{37}$, values similar to those reported for commercial potassium permanganate with a removal capacity of $91 \%$ of the ethylene present in a apple packaging system ${ }^{38}$.

Table 5: Adsorption isotherm parameters on $\mathrm{MtNa}^{+} \mathrm{y} \mathrm{NZ}-\mathrm{Ch}$.

\begin{tabular}{|c|c|c|c|c|}
\hline \multirow{2}{*}{ Muestra } & \multicolumn{4}{|c|}{ Langmuir-Freundlich model } \\
\cline { 2 - 5 } & $\begin{array}{c}q_{m} \\
\left(\mu 1 \mathrm{~g} \mathrm{~g}^{-1}\right)\end{array}$ & $\begin{array}{c}b \\
\left(\mathrm{ppm}^{-1}\right)\end{array}$ & $n$ & $R^{2}$ \\
\hline $\mathrm{MtNa}^{+}$ & 1.28034 & $5.61 \mathrm{E}-44$ & 0.0207 & 0.9985 \\
\hline $\mathrm{NZ}-\mathrm{Ch}$ & 5.41882 & 0.7841 & 0.7166 & 0.9982 \\
\hline
\end{tabular}

Between both aluminosilicate it is reasonable to select NZ-Ch as a mineral in which its intrinsic ethylene adsorption capacity could be improved in order to design a new ethylene scavenger to develop a new food packaging system oriented to increase the shelf-life of climacteric fruits.

Ethylene Adsorption on films

Figure 7 shows the ethylene adsorption kinetics of LDPE films with different NZ-Ch contents $(0,2.5,5,7.5,10 \% \mathrm{w} / \mathrm{w})$. It can be observed than LDPE film already presented a slight ethylene removal capacity, producing a decrease of the ethylene concentration in the headspace of $8 \%$ aproximately. On the other hand for the rest of the films, in the first 50 hours a fast reduction of the ethylene concentration can be observed, meanwhile after 50 hours the rate of the ethylene removal is much slower. The presence of NZ-Ch produces a decrease on the ethylene concentration in the headspace in accordance with the content of active mineral, reaching a decrease of $37 \%$ of the ethylene content for films containing $10 \%$ of ZN-Ch after $100 \mathrm{~h}$.
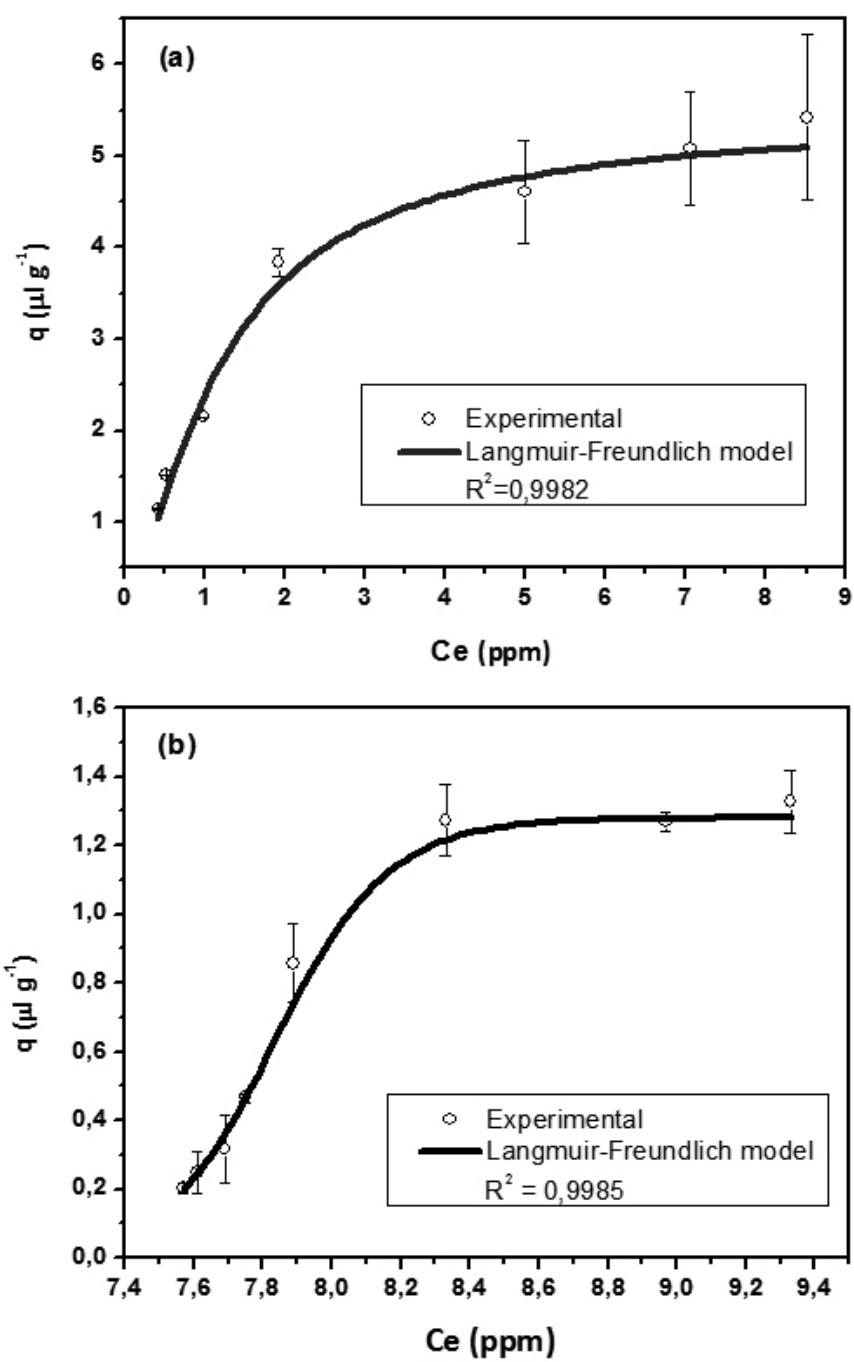

Figure 6: Adsorption isotherm at $25^{\circ} \mathrm{C}$; (a) $\mathrm{MtNa}^{+}$and (b) $\mathrm{NZ}-\mathrm{Ch}$.

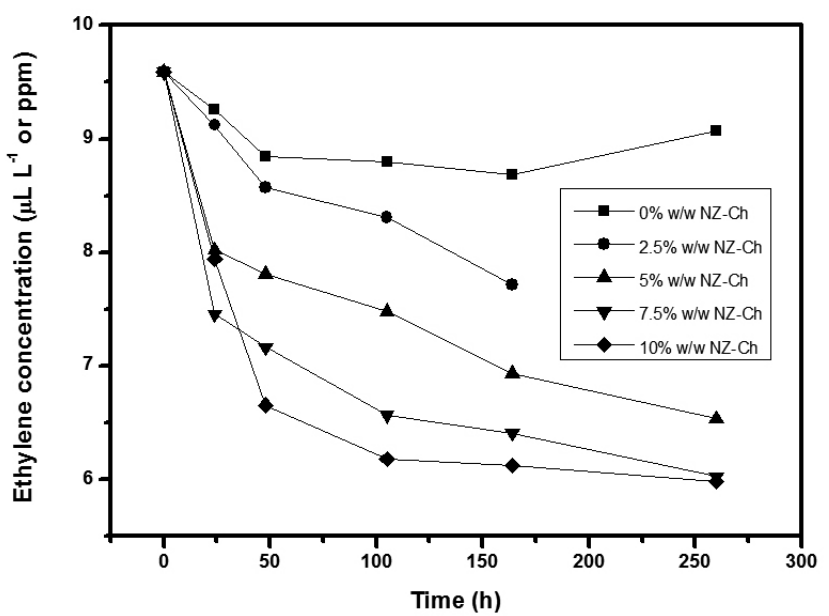

Figure 7: Ethylene adsorption on film of natural zeolite and LDPE. $\mathrm{Co}=$ $9.6 \mathrm{ppm} ; \mathrm{T}=25^{\circ} \mathrm{C} ; \mathrm{P}=1 \mathrm{~atm}$. 


\section{CONCLUSIONS}

In this study, the efficiency of a Chilean natural zeolite (NZ-Ch) against a commercial $\mathrm{Na}^{+}$montmorillonite $\left(\mathrm{Cloisite} \mathrm{Na}^{+}\right.$) was studied. The aluminosilicate characterization demostrated that natural Chilean zeolite belongs to mordenite group, and it presents a specific surface area of 607 $\mathrm{m}^{2} \mathrm{~g}^{-1}$, much higher that the specific surface area of Cloisite $\mathrm{Na}^{+}\left(49.8 \mathrm{~m}^{2} \mathrm{~g}^{-1}\right)$ Elemental chemical analysis indicated that as expected silicon and aluminium were the main elements of the both aluminosilicate, being the compensating ions, sodium for $\mathrm{MTNa}^{+}$and calcium, sodium and potassium for NZ-Ch. In both cases copper was present in their composition.

Ethylene adsorption kinetics were fitted to a pseudo-second order model. The rate constant of the ethylene adsorption was nearly double for NZ-Ch compared with $\mathrm{MtNa}^{+}$. Langmuir-Freundlich isotherm allowed to determine maximum adsorption capacity that reached values of 5.4 for NZ-Ch and 1.28 for CloisiteNa ${ }^{+}$.

Higher ethylene capacity of NZ-Ch was attributed to their porous structure and to the presence of copper as compensating cation, as it enhances adsorption properties of aluminosilicate, as act as a active site of adsorption.

\section{ACKNOWLEDGEMENTS}

The authors thanks to Fondo de Fomento al Desarrollo Científico y Tecnológico (Project FONDEF D11I1123) and Programa de Financiamiento Basal para Centros Científicos y Tecnológicos de Excelencia (Project FB0807). Alejandro Coloma thanks to Comisión Nacional de Investigación Científica y Tecnológica, CONICYT, for giving the National Doctoral Scholarship for Foreign Students.

\section{REFERENCES}

1. B. Erdoğan, M. Sakızcı, E. Yörükoğulları, Applied Surface Science $\mathbf{2 5 4}$ $2450,(2008)$

2. N. Patdhanagul, T. Srithanratana, K. Rangsriwatananon, S. Hengrasmee, Microporous and Mesoporous Materials 131, 97, (2010).

3. L. A. Terry, T. Ilkenhans, S. Poulston, L. Rowsell, A. W. J. Smith, Postharvest Biology and Technology 45, 214, (2007).

4. N. Patdhanagul, K. Rangsriwatananon, K. Siriwong, S. Hengrasmee, Microporous and Mesoporous Materials 153, 30, (2012).

5. V. K. Saini, M. Pinto, J. Pires, Separation Science and Technology 46, 137, (2011).

6. C. A. Ríos, L. Y. Vargas, in Earth and Environmental Sciences, I. A. Dar, M. A. Dar, Eds. InTech, Rijeka, 2011, pp. 363-374.

7. S. Navalon, M. Alvaro, H. Garcia, Applied Catalysis B: Environmental 99 , $1,(2010)$.

8. N. Sue-aok, T. Srithanratana, K. Rangsriwatananon, S. Hengrasmee, Applied Surface Science 256, 3997, (2010).

9. B. Erdoğan, M. Sakizci, Adsorption Science \& Technology 30, 265, (2012).

10. A. H. Englert, J. Rubio, Int. J. Miner. Process 75, 21, (2005).
11. C. d. R. Oliveira, J. Rubio, Materials Research 10, 407, (2007).

12. Y. Yukselen, A. Kaya, Journal of Geotechnical and Geoenvironmental Engineering 132, 931, (2006).

13. G. Montenegro, C. Fredes, E. Mejías, C. Bonomelli, L. Olivares, Agrociencia 43, 427, (2009).

14. B. L. R. Braga, C. I. G. L. Sarantópoulos, L. Peres, J. W. B. Braga, Packag. Technol. Sci. 23, 351, (2010).

15. M. J. Galotto, S. A. Anfossi, A. Guarda, Food Sci Tech Int 15, 159, (2009).

16. H. Nourmoradi, M. Khiadani, M. Nikaeen, Journal of Chemistry 2013, 1, (2013).

17. S. Hosseinpour, S. Fatemi, Y. Mortazavi, M. Gholamhoseini, M. T. Ravanchi, Separation Science and Technology 46, 349, (2011).

18. R. Zahedsheijani, H. Gholamiyan, A. Tarmian, H. Yousefi, Maderas. Ciencia y tecnología 13, 163, (2011).

19. S. I. S. Shahabadi, H. Garmabi, eXPRESS Polymer Letters 6, 657, (2012).

20. B. Lombardi, M. Baschini, R. M. Torres Sánchez, The Journal of the Argentina Chemical Society 90, 87, (2002).

21. M. L. Nguyen, C. C. Tanner, New Zealand Journal of Agricultural Research 41, 427, (1998).

22. C. Volzone, J. G. Thompson, A. Melnitchenko, J. Ortiga, S. R. Palethorpe, Clays and Clay Minerals 47, 647, (1999).

23. G. Aguilar-Armenta et al., J. Phys. Chem. B 105, 1313, (2001)

24. D. L. Carter, M. M. Mortland, W. D. Kemper, in Methods of Soil Analysis: Physical and mineralogical methods, Part I, A. Klute, A. L. Page, Eds. American Society of Agronomy, Michigan, 1986, vol. 9, pp. 413-423.

25. N. Widiastuti, H. Wu, H. M. Ang, D. Zhang, Desalination 277, 15 (2011).

26. A. N. Il'ichev, V. A. Matyshak, V. N. Korchak, Y. B. Yan, Kinetics and Catalysis. 42, 706 (2000).

27. J. E. Bruna, A. Peñaloza, A. Guarda, F. Rodríguez, M. J. Galotto, Applied Clay Science 58, 79, (2012).

28. F. J. Rodriguez, M. J. Galotto, A. Guarda, J. E. Bruna, Journal of Food Engineering 110, 262, (2012).

29. T. Nakamura, M. Ishikawa, T. Hiraiwa, J. Sato, Analytical Sciences 8, 539, (1992).

30. S. Sohrabnezhad, A. Rezaei, Superlattices and Microstructures 55, 168, (2013).

31. M. M. J. Treacy, J. B. Higgins, Collection of Simulated XRD Powder Patterns for Zeolites. Stucture Commision of the International Zeolite Association, USA, ed. Fourth, 2001.

32. C. Covarrubias, R. García, R. Arriagada, J. Yánez, M. T. Garland, Microporous and Mesoporous Mater. 88, 220, (2006).

33. H. A. Patel, R. S. Somani, H. C. Bajaj, R. V. Jasra, Applied Clay Science 35, 194, (2007).

34. A. R. Ramadan, A. M. K. Esawi, A. A. Gawad, Applied Clay Science 47, 196, (2010).

35. N. Mansouri, N. Rikhtegar, H. A. Panahi, F. Atabi, B. K. Shahraki, Environmental Protection Engineering 39, 139, (2013).

36. S. R. Taffarel, J. Rubio, Minerals Engineering 23, 771, (2010).

37. G. Peiser, T. V. Suslow, Perishables Handling Quarterly 17, 1, (1998).

38. R. B. H. Wills, M. A. Warton, J. Amer. Soc. Hort. Sci. 129, 433, (2004). 